\title{
Oncological Safety of Lipofilling in Patients with Breast Cancer: A Meta-analysis and Update on Clinical Practice
}

\author{
UMAR WAZIR $^{1}$, HIBA EL HAGE CHEHADE ${ }^{1}$, HANNAH HEADON ${ }^{1}$, \\ MEDHAT OTEIFA $^{2}$, ABDUL KASEM $^{1}$ and KEFAH MOKBEL ${ }^{1}$ \\ ${ }^{1}$ The London Breast Institute, The Princess Grace Hospital, London, U.K.; \\ ${ }^{2}$ Kuwait Cancer Control Centre, Al Sabah Medical District, Shuwaikh, Kuwait
}

\begin{abstract}
Background: Lipofilling is an increasingly popular technique for breast reconstruction following both mastectomy and breast-conserving surgery (BCS). However, concerns remain over its oncological safety and its effect on cancer recurrence. Materials and Methods: A systematic literature review and meta-analysis was carried out. Patients who had undergone mastectomy or BCS were investigated separately in order to find out whether the addition of lipofilling had a significant effect on locoregional recurrence rate. Results: Eleven studies were used in the analysis, yielding a total of 2,382 patients. For patients undergoing mastectomy (mean follow-up=36.2 months, range=12-90 months) or BCS (mean follow-up=30.2 months, range=12-60 months), the addition of lipofilling was not found to significantly affect the locoregional recurrence rate. Conclusion: This meta-analysis demonstrates that lipofilling is an oncologically safe procedure to be incorporated into breast reconstruction following either mastectomy or BCS for breast cancer. However, a careful oncological follow-up is recommended. In the future, more adequately powered controlled clinical trials are needed in order to fully understand long-term outcomes after lipofilling.
\end{abstract}

Lipofilling, or autologous fat transfer, is a technique which has been used for many years in the setting of aesthetic breast surgery. However, more recently, it has become popular in the management of breast reconstruction and treatment of volume defects following breast-conserving surgery (BCS), where its use can improve aesthetic results. Although gaining popularity in this setting, there are still questions regarding its oncological safety when used in patients being treated for breast cancer.

Correspondence to: Professor Kefah Mokbel, The London Breast Institute, The Princess Grace Hospital, 42-52 Nottingham Place, London W1U 5NY, U.K. E-mail: kefahmokbel@hotmail.com

Key Words: Mammaplasty, breast neoplasms, breast reconstruction, lipomodelling, transplantation, meta-analysis.
There are a number of advantages associated with lipofilling in the setting of breast reconstruction. The technique, developed by Bircoll, involves grafting small amounts of autologous fat into the subcutaneous breast tissue, allowing improved contouring of the breast shape whilst causing minimal trauma and scarring (1). It has been used not only to treat volume defects following lumpectomy procedures, but also to enhance the contour of the breast and improve the aesthetic outcome following both implant-based and autologous tissue-based reconstruction (2).

The harvested adipose tissue is a source of pre-adipose stem cells, which can promote angiogenesis and neoadipogenesis. The Coleman technique, which is currently the most commonly used methodology, capitalises on this property of adipose tissue by increasing the content of stem cells through centrifugation. This is believed to result in better volume retention and aesthetic results (3). However, recent in vitro studies have raised concerns by suggesting that breast cancer cells show increased rates of proliferation by interacting with these stem cells (4).

To our knowledge, there is no in vivo evidence regarding the effect of fat-derived stem cells on human breast cancer tissue. Recent clinical studies have suggested that it is a safe option in such women (5). However, the majority of the studies available are single-centre case series, which could pose a difficulty in drawing reliable and definitive conclusions with regards to safety and viability of this procedure. This study aimed to systematically evaluate the current literature regarding the oncological safety of lipofilling in patients who underwent surgical treatment for breast cancer by performing a meta-analysis to investigate the recurrence rates and the incidence of complications.

\section{Materials and Methods}

Literature search. A computer-aided literature search using the PubMed and Ovid databases was carried out in order to identify relevant articles for inclusion in the study up to January 2016 with no lower limit. Search terms such as 'oncological safety AND lipofilling', 'breast cancer AND lipofilling AND safety' and 'breast 
cancer AND lipofilling AND recurrence' were used to search for articles. The similar articles feature was also utilised when using PubMed and the bibliographies of relevant articles were analysed to ensure all eligible research was included. Possible abstracts were reviewed to identify full text manuscripts which could be reviewed for inclusion in the study.

Inclusion criteria. To be included in the meta-analysis, articles had to have investigated female patients who were being treated for breast cancer with either BCS or mastectomy. Patients had to be treated with lipofilling as part of their reconstructive surgery. Patients treated with lipofilling for purely aesthetic reasons were excluded from the study. Articles had to specify how many patients underwent $\mathrm{BCS}$ and mastectomy and the recurrence rate for each group.

Reviews, letters, commentaries and case studies were excluded from the study. Only articles written in English were included.

Data extraction. All articles deemed eligible for inclusion in the current meta-analysis were read in full by one of the authors in order to extract relevant data. Publication date, country of study, study design, number of participants, median age, number of patients undergoing mastectomy and BCS, number of recurrences in each group, use of radiotherapy and complication rate, including The nature of complications, were extracted from each article.

Statistical analysis. Following data extraction, a meta-analysis was performed to assess whether there was a significant oncological risk with the use of lipofilling, both for women treated with mastectomy and those treated with BCS. Meta-regression technique was used using lipofilling as the explanatory variable. All statistical tests were performed in the Comprehensive Meta-Analysis Software v2 (Biostat, Inc., NJ, USA).

\section{Results}

Our literature search yielded a total of 11 studies which reported on locoregional recurrence rate in patients who had undergone lipofilling as part of their breast reconstruction procedure. Ten out of 11 studies were carried out in Europe and one study was reported from Brazil. As discussed above, we analyzed data of those who had undergone mastectomy and those who had undergone BCS separately. The Coleman technique was the commonest method used and most studies did not report the fat volume transferred to the breast. The median total fat transferred to the breast was $99 \mathrm{cc}$.

Mastectomy. Nine studies reported on patients who had undergone mastectomy and subsequent lipofilling (5-13) (Table I) yielding 1,756 procedures. Six out of the nine studies were prospective and four used control groups. The mean age of patients across studies was 51.5 years. The mean follow-up was 36.2 months (median=29 months, range $=12-90$ months.) The mean locoregional recurrence rate was $3.2 \%$ with a median of $2.0 \%$ (range $=0-8.5 \%$ ).

A meta-analysis was performed using a meta-regression technique with historical controls (14-28). Results of the analysis are summarised in Figure 1. There was only a small difference between the pooled values for locoregional recurrence rate of those who had undergone mastectomy and lipofilling and those who had undergone mastectomy only. The pooled estimate of logit recurrence rate in procedures without lipofilling was found to be -3.192 , equivalent to a $4 \%$ locoregional recurrence rate. The slope of the regression curve represented the change in logit recurrence rate once lipofilling was performed after mastectomy. The slope was found to be -0.228 , equivalent to a recurrence rate of $3.2 \%$. However, this difference was insignificant $(p=0.497)$. Therefore, we can conclude that practice of lipofilling does not significantly increase the locoregional recurrence rate after mastectomy.

Breast-conserving surgery. Ten studies reported on locoregional recurrence rate following BCS $(5-7,9,10,12$, 29-32) (Table II) and lipofilling, three of which used controls. This yielded a total of 651 procedures. The mean follow-up was 30.2 months (median=27 months, range $=12$ 60 months). The mean locoregional recurrence rate of those undergoing lipofilling was $4.5 \%$, with a median of $1.3 \%$ (range $=0-16.7 \%$ ).

A meta-analysis was again performed using a metaregression technique with historical control data to increase reliability (14-28). Figure 2 illustrates the result. The flat regression line indicates little difference between the pooled values. Again, using a meta-regression method using lipofilling as the explanatory variable, the intercept represented the pooled estimate of logit recurrence rate in procedures without lipofilling, in this case found to be -3.015 , equivalent to a pooled locoregional recurrence rate of $4.7 \%$. The slope represented the change in logit recurrence rate when lipofilling was performed after BCS, which was found to be 0.004 , equivalent to a locoregional recurrence rate of $4.7 \%$. However, this difference was insignificant $(p=0.992)$. We can, therefore, conclude that lipofilling practice does not significantly increase locoregional recurrence rate after BCS.

\section{Discussion}

Lipofilling is a procedure which is growing in popularity and is increasingly used in breast surgery, and this is evident in the increasing number of publications on this subject. However, much of the literature concerns the technical aspect of the lipofilling procedure rather than the complications and outcomes. This is evidenced by the small number of published studies that used control groups for comparison (33).

Petit and colleagues conducted one of the largest studies investigating the use of lipofilling in 321 patients compared with 642 controls who did not undergo lipofilling (13). Controls were matched for surgery date (within 2 years), age 
Table I. Studies regarding the use of lipofilling post-mastectomy for breast cancer.

\begin{tabular}{|c|c|c|c|c|c|c|c|c|}
\hline Study & Ref & Design & $\begin{array}{c}\text { Total } \\
\text { procedures, } \\
\mathrm{n}\end{array}$ & $\begin{array}{c}\text { Total } \\
\text { mastectomies, } \\
\mathrm{n}\end{array}$ & $\begin{array}{c}\text { Study group } \\
\text { (with lipofilling), } \\
\mathrm{n}\end{array}$ & $\begin{array}{l}\text { Control } \\
\text { group, } \\
\mathrm{n}\end{array}$ & $\begin{array}{l}\text { Locoregional } \\
\text { recurrence in study } \\
\text { group, } \mathrm{n}(\%)\end{array}$ & $\begin{array}{l}\text { Locoregional } \\
\text { recurrence in control } \\
\text { group, } \mathrm{n}(\%)\end{array}$ \\
\hline Silva-Vegara et al. 2016 & 6 & Prospective & 195 & 132 & 132 & NA & $8(6)$ & NA \\
\hline Chirappapha et al. 2015 & 7 & Retrospective & 137 & 85 & 85 & NA & $0(0)$ & NA \\
\hline Masia et al. 2015 & 8 & Retrospective & 214 & 214 & 107 & 107 & $6(5.6)$ & $6(5.6)$ \\
\hline Kronowitz et al. 2016 & 9 & Prospective & 1389 & 1230 & 639 & 591 & $8(1.3)$ & 11(1.9) \\
\hline Petit et al. 2013 & 10 & Prospective & 177 & 141 & 47 & 94 & $4(8.5)$ & $3(3.2)$ \\
\hline Riggio et al. 2013 & 11 & Prospective & 60 & 60 & 60 & NA & $2(3.3)$ & NA \\
\hline Costantini et al. 2013 & 12 & Prospective & 22 & 14 & 14 & NA & $0(0)$ & NA \\
\hline Petit et al. 2012 & 5 & Retrospective & 963 & 588 & 196 & 392 & $4(2.0)$ & $18 *$ \\
\hline Petit et al. 2011 & 13 & Retrospective & 646 & 476 & 476 & NA & $8(1.7)$ & NA \\
\hline
\end{tabular}

*Overall locoregional recurrence rate across all controls, including both mastectomy and breast-conserving surgery.

Table II. Studies regarding the use of lipofilling after breast-conserving surgery (BCS) for breast cancer.

\begin{tabular}{|c|c|c|c|c|c|c|c|c|}
\hline Study & Ref & Design & $\begin{array}{c}\text { Total } \\
\text { procedures, } \\
\mathrm{n}\end{array}$ & $\begin{array}{c}\text { Total number } \\
\text { BCS, } \\
\text { n }\end{array}$ & $\begin{array}{c}\text { Study group } \\
\text { (with lipofilling), } \\
\text { n }\end{array}$ & $\begin{array}{l}\text { Control } \\
\text { group, } \\
\mathrm{n}\end{array}$ & $\begin{array}{l}\text { Locoregional } \\
\text { recurrence in study } \\
\text { group }, \mathrm{n}(\%)\end{array}$ & $\begin{array}{l}\text { Locoregional } \\
\text { recurrence in control } \\
\text { group, } \mathrm{n}(\%)\end{array}$ \\
\hline Silva-Vegara et al. 2016 & 6 & Prospective & 195 & 63 & 63 & NA & $2(3.2)$ & NA \\
\hline Garcia et al. 2016 & 29 & Prospective & 37 & 37 & 37 & NA & $0(0)$ & NA \\
\hline Mestak et al. 2016 & 30 & Prospective & 77 & 77 & 32 & 45 & $2(6.3)$ & $2(4.4)$ \\
\hline Chirappapha et al. 2015 & 7 & Retrospective & 137 & 52 & 52 & NA & $0(0)$ & NA \\
\hline Semprini et al. 2014 & 31 & Prospective & 151 & 151 & 151 & NA & $0(0)$ & NA \\
\hline Kronowitz et al. 2016 & 9 & Prospective & 1389 & 152 & 79 & 73 & $1(1.3)$ & $4(5.5)$ \\
\hline Petit et al. 2013 & 10 & Prospective & 177 & 36 & 12 & 24 & $2(16.7)$ & $0(0)$ \\
\hline Costantini et al. 2013 & 12 & Prospective & 22 & 8 & 8 & NA & $1(12.5)$ & NA \\
\hline Petit et al. 2012 & 5 & Retrospective & 963 & 375 & 125 & 250 & $1(2.4)$ & $18 *$ \\
\hline Pérez-Cano et al. 2012 & 32 & prospective & 92 & 68 & 68 & NA & $0(0)$ & NA \\
\hline
\end{tabular}

*Locoregional recurrence rate was of all controls, including both those who underwent mastectomy and those who underwent BCS.

(within 5 years), tumour size, histology, type of surgery and oestrogen receptor status. Eighty-nine percent of tumours were invasive. The median follow-up was 59 months from initial resection, and then 26 months from lipofilling procedure. They reported no significant difference in recurrence rate between the controls and the study group following mastectomy nor BCS, until analysis was limited to intraepithelial neoplasia, in which the use of lipofilling was found to significantly increase the risk of recurrence (10). This is echoed by results from Kronowitz and colleagues in a recent case-control study, who also found no significant difference in the rates of locoregional recurrence between those who had undergone lipofilling and those who had not. They found an increased locoregional recurrence rate in only one subgroup, those who had undergone hormonal therapy and lipofilling. They hypothesised that there may be a potential role for hormonal therapy in enhancing a tumorigenic microenvironment and perhaps enhancing cross-talk between adipocytes and tumour cells. However, the authors stress that it is not known whether this does or even can occur (9).

Lipofilling has many inherent benefits for the use in breast reconstruction, being able to correct volume defects with minimal scarring, improving aesthetic results, and leading to an increased patient satisfaction rate (34). Another advantage cited for lipofilling is the near-limitless supply of highquality donor material, which compensates for the postfilling loss of volume (1). Sarfati et al. also reported favourable results after preliminary lipofilling to the chest wall following mastectomy and irradiation, indicating that lipofilling may have wider indications than previously thought (35).

The main concern with the use of lipofilling in breast reconstruction is that it may increase the rate of recurrence. This is especially the case in the setting of BCS, where lipofilling is often used to repair the defect left by 


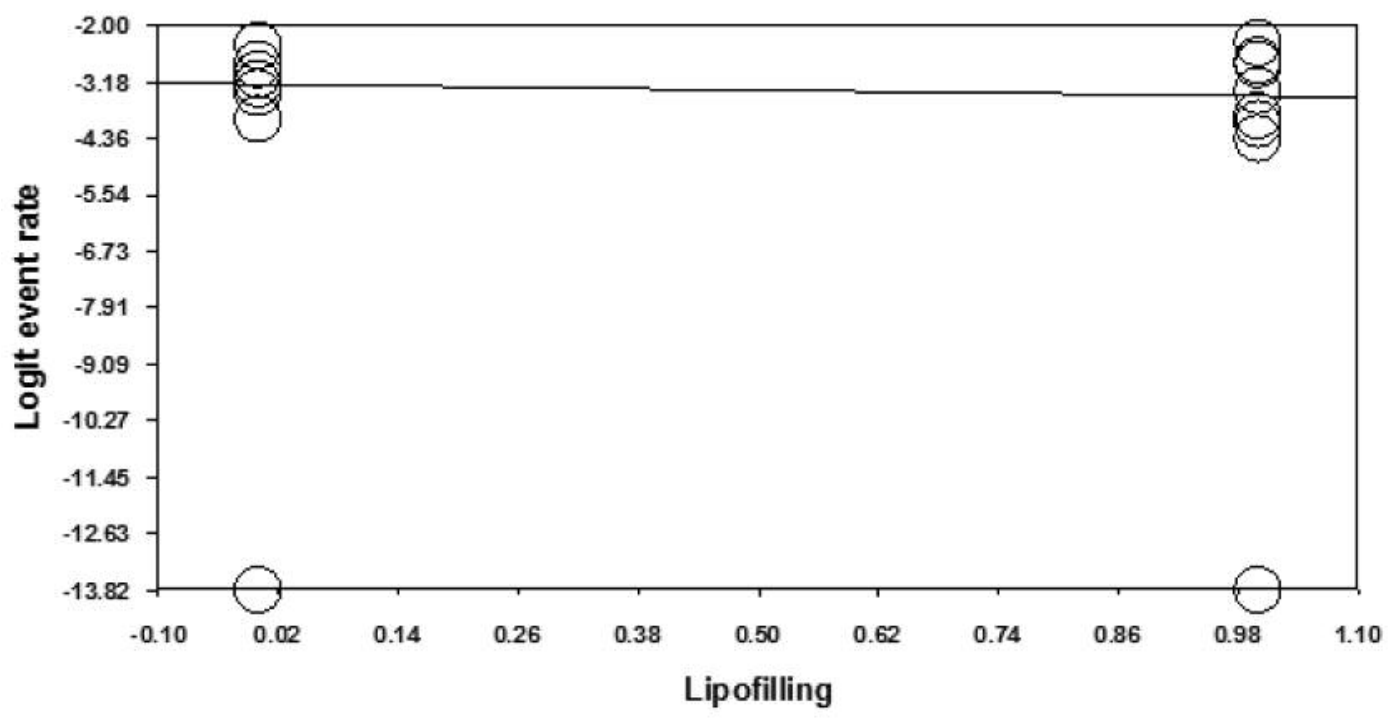

Mixed effects regression (method of moments)

\begin{tabular}{|c|c|c|c|c|c|}
\hline & Point estimate & Standard error & Lower limit & Upper limit & $p$-Value \\
\hline Slope & -0.228 & 0.336 & -0.887 & 0.430 & 0.497 \\
\hline Intercept & -3.192 & 0.236 & -3.655 & -2.730 & 0.000 \\
\hline \multirow[t]{2}{*}{ Tau-squared } & 0.199278175 & & & & \\
\hline & Q & df & $p$-Value & & \\
\hline Model & 0.462 & 1 & 0.497 & & \\
\hline Residual & 13.028 & 15 & 0.600 & & \\
\hline Total & 13.490 & 16 & 0.637 & & \\
\hline
\end{tabular}

Figure 1. Regression of lipofilling on logit event rate. The left part of the graph presents the distribution of the local recurrence rate (expressed as logit) for studies where lipofilling was not applied following mastectomy. The right-hand side of the graph is the distribution of local recurrence rate (expressed as logit) for studies with lipofilling after mastectomy. In both cases, pooled values are on about the same level (the regression line is flat). The intercept of -3.192 represents the pooled estimate of logit recurrence rate for all studies without lipofilling and is equivalent to a $3.2 \%$ recurrence rate.

lumpectomy. Questions surrounding whether adipose tissue can promote growth of residual tumour cells have led to concerns regarding oncological safety. A number of in vitro studies have shown that adiocyte aspirate can induce tumour cell growth. Massa et al. conducted an in vitro study looking at the interaction of adipose tissue derived from lipofilling procedures with breast cancer cells from a number of cell lines and found that proliferation of cancer cells was enhanced when they were incubated with unfiltered lipoaspirate. They also found that bone marrow fibroblasts, in comparison, did not induce significant increase in proliferation of tumour cells. These findings suggest that a component of adipose tissue may be contributory to increased proliferation. This effect does not appear to be restricted to breast cancer cells (4). Perrot et al. reported an unusual case of osteosarcoma recurrence which occurred 13 years after the initial diagnosis and 18 months after lipofilling. It is unusual to see a recurrence of osteosarcoma so late, and preclinical models confirmed that adipocytes or their progenitor cells promoted osteosarcoma tumour growth (36). Despite such evidence from in vitro studies, these results have not been replicated or supported by in vivo 


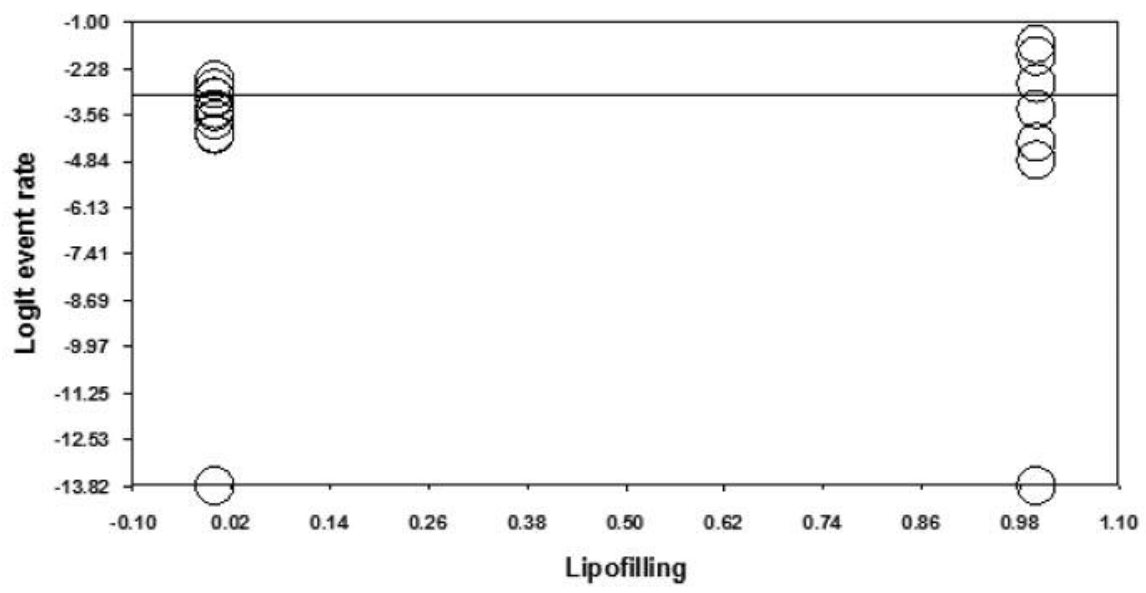

Mixed effects regression (method of moments)

\begin{tabular}{|c|c|c|c|c|c|}
\hline & Point estimate & Standard error & Lower limit & Upper limit & $p$-Value \\
\hline Slope & -0.004 & 0.365 & -0.718 & 0.711 & 0.992 \\
\hline Intercept & -3.015 & 0.116 & -3.243 & -2.788 & 0.000 \\
\hline Tau-squared & 0 & & & & \\
\hline & $Q$ & df & $p$-Value & & \\
\hline Model & 0.000 & 1 & 0.992 & & \\
\hline Residual & 22.783 & 23 & 0.473 & & \\
\hline Total & 22.784 & 24 & 0.533 & & \\
\hline
\end{tabular}

Figure 2. Regression of lipofilling on logit event rate. The left part of graph presents distribution of local recurrence rate (expressed as logit) for studies where lipofilling was not applied following breast-conserving surgery. The right-hand side of the graph is distribution of local recurrence rate (expressed as logit) for studies with lipofilling after breast-conserving surgery. In both cases, pooled values are on about the same level (the regression line is flat). Here the intercept of -3.015 represents the pooled estimate of logit recurrence rate for all studies without lipofilling that is equivalent to a $4.7 \%$ recurrence rate.

studies. Indeed, clinical trial data as collated in our metaanalysis suggest that these findings are limited to in vitro settings with no discernible translation in vivo, for reasons as yet unclear. This may be addressed by widening the ongoing debate regarding stem cell recruitment in breast cancer to consider the implications for implanted adipocytederived stem cells (37).

Another major concern regarding lipofilling is the loss of retained volume after grafting. This was recognised very early on, and was cited as the reason for the failure of earlier attempts of lipofilling to gain currency (38). This loss of volume is in part due to transplantation of non-viable material, and due to liponecrosis of the graft (39). The current methods of lipofilling improve retained volume through refinements of fat harvesting, and by processing the fat before implanting it in the recipient site. Previous techniques of lipofilling did not involve any processing of the tissue (38).
Described methods of fat harvesting are broadly similar. Donor tissue is engorged with tumescent fluid, which consists of saline, epinephrine, and a local anaesthetic. The fat is harvested through stab incisions using a blunt cannula (40).

Methods of fat processing can vary greatly. The canonical method described by Bircoll involved treating the fat with insulin (1). Others have recommended coenzyme Q10 and vascular endothelial growth factor $(41,42)$. However, the most prevalent method is the one described by Coleman, in which the fat is refined by centrifugation, allowing the supernatant fat and lower aqueous layers to be discarded, leaving only viable cells, which are less likely to be resorbed. The majority of the studies included in our analysis employed this method (43). At least one author recommended sedimentation as opposed to centrifugation (44). Cell-assisted lipo-transfer is a further refinement of 
this technique, described by Matsumoto et al., in which the fat is enriched with adipose-derived stem cells, either by centrifugation or by ex vivo culturing before implantation (45). This method showed promise in a recent randomised trial against placebo (46). Pèrez-cano et al. described the use of adipose-derived regenerative cell-enriched fat grafting, demonstrating the safety and efficacy of this procedure (32). Other methods prevalent include the Berlin autologous lipo-transplantation system, which is a proprietary closed circuit fat harvesting and processing system using water jets (47), and the BRAVA system, which involves mega-volume transfer of autologous fat after preexpanding the breasts using proprietary BRAVA devices over a prolonged period of time $(48,49)$. However, externally validated studies comparing these various techniques are still very limited.

An early concern regarding the use of lipofilling in the breast was the potential for artifacts caused by lipofilling to interfere with radiological screening and follow-up. In fact, this was cited in an early recommendation of the American Society of Plastic Surgery (ASPS) against the use of lipofilling in the breast (39). However, subsequent studies have shown that the changes resulting from fat injection can be easily distinguished from neoplastic images, and would not interfere with radiological screening (50-52). Such evidence enabled the ASPS to revise their recommendation, withdrawing any reservations regarding lipofilling and breast screening (53).

Local complications associated with lipofilling include liponecrosis, oil cyst formation, calcifications, haematomas, infection, and donor site complications. Of these, liponecrosis is regarded as the of the more common of the complications of the procedure (29). However, more recent studies have shown relatively low liponecrosis rates: Petit et al. reported a liponecrosis rate of $2.0 \%$ in 646 procedures (13), as opposed to that reported by the ASPS, who reported a liponecrosis rate of $5.7 \%$ (52). However, a more recent study reported a liponecrosis and oil cyst formation rate of $7.2 \%$ in 319 procedures (6), and another reported a rate of $7 \%$ in an elderly population (7). Despite this, other studies have reported a rate of $0 \%(35,47,49,54,55)$. The varying rates of liponecrosis may be due to a number of factors: differing follow-up times, differences in investigation procedure for complications or differing patient population. It is also important to note that most of the liponecrosis described may not be clinically significant as a contributor to volume loss: one author described how many of the complications were discovered on routine ultrasound examination and were of no clinical significance (6). However, liponecrosis can on occasion lead to significant clinical sequelae, including sepsis and lymphadenitis (56). Therefore, the risk of liponecrosis cannot be completely discounted, and the factors contributing to it should be better understood. Chirappapha et al. began this process in a recent study investigating complications of lipofilling. They found that there was no significant relationship between volume of fat injected, number of procedures, use of locoregional radiotherapy, age or comorbidity status and complication rate (7). However, this study was limited to an elderly population, which may not reflect the typical patient population.

This study is not without its limitations. Due to the small amount of published literature involving controlled trials with lipofilling in breast cancer, we had to use historical controls from previously published trials regarding recurrence after mastectomy or BCS. Additionally, the inclusion of studies only written English may mean that relevant studies were missed from the analysis. Moreover, the follow-up of the included studies varied widely, with the shortest being just 12 months (12) arguably not enough time to evaluate the recurrence rate. The included studies also did not report consistently on factors found to affect recurrence rate, such as tumour size, tumour stage and use of adjuvant therapies. The studies analysed had significant heterogeneity and therefore we had to use the mixed-effects rather than the fixed-effect model in the analysis. In the future, controlled trials need to be conducted which control for all these variables in order to identify patients who may not be suitable for lipofilling, if such a subset exists. Furthermore, the optimal interval between breast cancer surgery and lipofilling should be determined.

\section{Conclusion}

Through this analysis, involving 2,407 patients, we found no evidence that lipofilling significantly increases the risk of locoregional recurrence when used as part of a breast reconstruction procedure after either mastectomy or BCS for breast cancer and can be therefore considered an oncologically safe procedure in suitable patients with careful oncological follow-up. In the future, more long-term, adequately powered, multicentre controlled studies are needed. Additionally, more research should be carried out on the incidence of complications following lipofilling so that efforts can be made to prevent them and optimise fat graft survival.

\section{Acknowledgements}

This review was funded by grants from the Breast Cancer Hope Foundation (London, UK).

\section{Conflicts of Interest}

None of the Authors declare any conflicts of interest in regard to this study. 


\section{References}

1 Bircoll M: Cosmetic breast augmentation utilizing autologous fat and liposuction techniques. Plast Reconstr Surg 79(2): 267271, 1987.

2 Panettiere P, Marchetti L and Accorsi D: The serial free fat transfer in irradiated prosthetic breast reconstructions. Aesthetic Plast Surg 33(5): 695-700, 2009.

3 Bucky LP and Percec I: The science of autologous fat grafting: views on current and future approaches to neoadipogenesis. Aesthet Surgery J 28(3): 313-21; quiz 322-324, 2008.

4 Massa M, Gasparini S, Baldelli I, Scarabelli L, Santi P, Quarto $\mathrm{R}$ and Repaci E: Interaction between breast cancer cells and adipose tissue cells derived from fat grafting. Aesthet Surg J 36(3): 358-363, 2016.

5 Petit JY, Botteri E, Lohsiriwat V, Rietjens M, De Lorenzi F, Garusi C, Rossetto F, Martella S, Manconi A, Bertolini F, Curigliano G, Veronesi P, Santillo B and Rotmensz N: Locoregional recurrence risk after lipofilling in breast cancer patients. Ann Oncol 23(3): 582-588, 2012.

6 Silva-Vergara C, Fontdevila J, Descarrega J, Burdio F, Yoon TS and Grande L: Oncological outcomes of lipofilling breast reconstruction: 195 consecutive cases and literature review. J J Plast Reconstr Aesthet Surg 69(4): 475-481, 2016.

7 Chirappapha P, Rietjens M, De Lorenzi F, Andrea M, Hamza A, Petit JY, Garusi C, Martella S, Barbieri B and Gottardi A: Evaluation of lipofilling safety in elderly patients with breast cancer. Plast Reconstr Surg Glob Open 3(7): e441, 2015.

8 Masia J, Bordoni D, Pons G, Liuzza C, Castagnetti F and Falco G: Oncological safety of breast cancer patients undergoing freeflap reconstruction and lipofilling. E Eur J Surg Oncol 41(5): 612-616, 2015.

9 Kronowitz SJ, Mandujano CC, Liu J, Kuerer HM, Smith B, Garvey P, Jagsi R, Hsu L, Hanson S and Valero V: Lipofilling of the breast does not increase the risk of recurrence of breast cancer: a matched controlled study. Plast Reconstr Surg 137(2): 385-393, 2016.

10 Petit JY, Rietjens M, Botteri E, Rotmensz N, Bertolini F, Curigliano G, Rey P, Garusi C, De Lorenzi F, Martella S, Manconi A, Barbieri B, Veronesi P, Intra M, Brambullo T, Gottardi A, Sommario M, Lomeo G, Iera M, Giovinazzo V and Lohsiriwat V: Evaluation of fat grafting safety in patients with intraepithelial neoplasia: a matched-cohort study. Ann Oncol 24(6): 1479-1484, 2013.

11 Riggio E, Bordoni D and Nava MB: Oncologic surveillance of breast cancer patients after lipofilling. Aesthetic Plast Surg 37(4): 728-735, 2013.

12 Costantini M, Cipriani A, Belli P, Bufi E, Fubelli R, Visconti G, Salgarello $\mathrm{M}$ and Bonomo L: Radiological findings in mammary autologous fat injections: a multi-technique evaluation. Clin Radiol 68(1): 27-33, 2013

13 Petit JY, Lohsiriwat V, Clough KB, Sarfati I, Ihrai T, Rietjens M, Veronesi P, Rossetto F, Scevola A and Delay E: The oncologic outcome and immediate surgical complications of lipofilling in breast cancer patients: a multicenter study--MilanParis-Lyon experience of 646 lipofilling procedures. Plast Reconstr Surg 128(2): 341-346, 2011.

14 Aalders KC, Postma EL, Strobbe LJ, van der Heiden-van der Loo M, Sonke GS, Boersma LJ, van Diest PJ, Siesling S and van Dalen T: Contemporary locoregional recurrence rates in young patients with early-stage breast cancer. J Clin Oncol 34(18): 2107-2114, 2016.

15 Achard E and Salmon RJ: Reduction mammoplasty in breast cancers of the lower quadrants. Bull Cancer 94(2): 225-228, 2007.

16 Caruso F, Catanuto G, De Meo L, Ferrara M, Gallodoro A, Petrolito E, Trombetta G and Castiglione G: Outcomes of bilateral mammoplasty for early stage breast cancer. Eur J Surg Oncol 34(10): 1143-1147, 2008.

17 Chakravorty A, Shrestha AK, Sanmugalingam N, Rapisarda F, Roche N, Querci Della Rovere G and Macneill FA: How safe is oncoplastic breast conservation? Comparative analysis with standard breast conserving surgery. Eur J Surg Oncol 38(5): 395398, 2012.

18 Denewer A, Shahatto F, Elnahas W, Farouk O, Roshdy S, Khater A, Hussein O, Teima S, Hafez M, Zidan S, Shams N and Kotb $\mathrm{S}$ : Therapeutic reduction mammoplasty in large-breasted women with cancer using superior and superomedial pedicles. Breast Cancer 4: 167-172, 2012.

19 Fitoussi AD, Berry MG, Fama F, Falcou MC, Curnier A, Couturaud B, Reyal F and Salmon RJ: Oncoplastic breast surgery for cancer: analysis of 540 consecutive cases [outcomes article]. Plast Reconstr Surg 125(2): 454-462, 2010.

20 Gendy RK, Able JA and Rainsbury RM: Impact of skin-sparing mastectomy with immediate reconstruction and breast-sparing reconstruction with miniflaps on the outcomes of oncoplastic breast surgery. Br J Surg 90(4): 433-439, 2003.

21 Grubnik A, Benn C and Edwards G: Therapeutic mammaplasty for breast cancer: oncological and aesthetic outcomes. World J Surg 37(1): 72-83, 2013.

22 Hernanz F, Sanchez S, Cerdeira MP and Figuero CR: Long-term results of breast conservation and immediate volume replacement with myocutaneous latissimus dorsi flap. World J Surg Oncol 9: 159, 2011.

23 Huemer GM, Schrenk P, Moser F, Wagner E and Wayand W: Oncoplastic techniques allow breast-conserving treatment in centrally located breast cancers. Plast Reconstr Surg 120(2): 390-398, 2007.

24 McCulley SJ and Macmillan RD: Therapeutic mammaplasty-analysis of 50 consecutive cases. Br J Plast Surg 58(7): 902-907, 2005.

25 Meretoja TJ, Svarvar C and Jahkola TA: Outcome of oncoplastic breast surgery in 90 prospective patients. Am J Surg 200(2): 224-228, 2010.

26 Nano MT, Gill PG, Kollias J and Bochner MA: Breast volume replacement using the latissimus dorsi miniflap. ANZ J Surg 74(3): 98-104, 2004.

27 Noguchi M, Minami M, Earashi M, Taniya T, Miyazaki I, Nishijima H, Takanaka T, Kawashima H, Saito Y and Nakamura S: Oncologic and cosmetic outcome in patients with breast cancer treated with wide excision, transposition of adipose tissue with latissimus dorsi muscle, and axillary dissection followed by radiotherapy. Breast Cancer Res Treat 35(2): 163-171, 1995.

28 Rietjens M, Urban CA, Rey PC, Mazzarol G, Maisonneuve P, Garusi C, Intra M, Yamaguchi S, Kaur N, De Lorenzi F, Matthes AG, Zurrida S and Petit JY: Long-term oncological results of breast conservative treatment with oncoplastic surgery. Breast 16(4): 387-395, 2007.

29 Molto Garcia R, Gonzalez Alonso V and Villaverde Domenech ME: Fat grafting in immediate breast reconstruction. Avoiding breast sequelae. Breast Cancer 23(1): 134-140, 2016. 
30 Mestak O, Hromadkova V, Fajfrova M, Molitor M and Mestak $\mathrm{J}$ : Evaluation of oncological safety of fat grafting after breastconserving therapy: a prospective study. Ann Surg Oncol 23(3): 776-781, 2016.

31 Semprini G, Cattin F, Zanin C, Lazzaro L, Cedolini C, Vaienti L, and Parodi PC: About locoregional recurrence risk after lipofilling in breast cancer patients: our experience. Minerva Chir 69(2): 91-96, 2014.

32 Perez-Cano R, Vranckx JJ, Lasso JM, Calabrese C, Merck B, Milstein AM, Sassoon E, Delay E and Weiler-Mithoff EM: Prospective trial of adipose-derived regenerative cell (ADRC)enriched fat grafting for partial mastectomy defects: the RESTORE-2 trial. Eur J Surg Oncol 38(5): 382-389, 2012.

33 Kasem A, Wazir U, Headon H and Mokbel K: Breast lipofilling: a review of current practice. Arch Plast Surg 42(2): 126-130, 2015.

34 Ho Quoc C, Foyatier JL, Meruta A, Piat JM, Michel G, and Delay E: Lipofilling, an efficient solution for breast sequelae after cardiothoracic surgery. Ann Chir Plast Esthet 60(6): 522526,2015

35 Sarfati I, Ihrai T, Kaufman G, Nos C and Clough KB: Adiposetissue grafting to the post-mastectomy irradiated chest wall: preparing the ground for implant reconstruction. J Plast Reconstr Aesthet Surg 64(9): 1161-1166, 2011.

36 Perrot P, Rousseau J, Bouffaut AL, Rédini F, Cassagnau E, Deschaseaux F, Heymann MF, Heymann D, Duteille F, Trichet $\mathrm{V}$ and Gouin F: Safety concern between autologous fat graft, mesenchymal stem cell and osteosarcoma recurrence. PloS One 5(6): e 10999, 2010.

37 Ajani JA, Song S, Hochster HS and Steinberg IB: Cancer stem cells: the promise and the potential. Semin Oncol 42(Suppl 1): S3-17, 2015.

38 Peer LA: Loss of volume in human fat grafts. Plast Reconstr Surg 5: 217, 1950 .

39 ASPRS Ad-Hoc Committee on New Procedures. Report on autologous fat transplantation. Plast Surg Nurs 7(4): 140-141, 1987.

40 Klein JA: Tumescent technique for local anesthesia improves safety in large-volume liposuction. Plast Reconstr Surg 92(6): 1085-1098; discussion 99-100, 1993.

41 Witort EJ, Pattarino J, Papucci L, Schiavone N, Donnini M, Lapucci A, Lulli M, Lo Russo G, Mori A, Dini M and Capaccioli S: Autologous lipofilling: coenzyme Q10 can rescue adipocytes from stress-induced apoptotic death. Plast Reconstr Surg 119(4): 1191-1199, 2007.

42 Chung CW, Marra KG, Li H, Leung AS, Ward DH, Tan H, Kelmendi-Doko A and Rubin JP: VEGF microsphere technology to enhance vascularization in fat grafting. Ann Plast Surg 69(2): 213-219, 2012

43 Coleman SR: Hand rejuvenation with structural fat grafting. Plast Reconstr Surg 110(7): 1731-1744; discussion 45-47, 2002.

44 Rubino C, Mazzarello V, Faenza M, Montella A, Santanelli F and Farace F: A Scanning electron microscope study and statistical analysis of adipocyte morphology in lipofilling: comparing the effects of harvesting and purification procedures with 2 different techniques. Ann Plast Surg 74(6): 718-721, 2013 .
45 Matsumoto D, Sato K, Gonda K, Takaki Y, Shigeura T, Sato T, Aiba-Kojima E, lizuka F, Inoue K, Suga H and Yoshimura K: Cell-assisted lipotransfer: supportive use of human adiposederived cells for soft tissue augmentation with lipoinjection. Tissue Eng 12(12): 3375-3382, 2006.

46 Kolle SF, Fischer-Nielsen A, Mathiasen AB, Elberg JJ, Oliveri RS, Glovinski PV, Kastrup J, Kirchhoff M, Rasmussen BS, Talman ML, Thomsen C, Dickmeiss E and Drzewiecki KT: Enrichment of autologous fat grafts with ex vivo expanded adipose tissue-derived stem cells for graft survival: a randomised placebo-controlled trial. Lancet 382(9898): 1113-1120, 2013.

47 Ueberreiter K, von Finckenstein JG, Cromme F, Herold C, Tanzella U and Vogt PM: BEAULI--a new and easy method for large-volume fat grafts. Handchir Mikrochir Plast Chir 42(6): 379-385, 2010.

48 Khouri RK, Eisenmann-Klein M, Cardoso E, Cooley BC, Kacher D, Gombos E and Baker TJ: Brava and autologous fat transfer is a safe and effective breast augmentation alternative: results of a 6-year, 81-patient, prospective multicenter study. Plast Reconstr Surg 129(5): 1173-1187, 2012.

49 Del Vecchio DA and Bucky LP: Breast augmentation using preexpansion and autologous fat transplantation: a clinical radiographic study. Plast Reconstr Surg 127(6): 2441-2450, 2011.

50 Rubin JP, Coon D, Zuley M, Toy J, Asano Y, Kurita M, Aoi N, Harii $\mathrm{K}$ and Yoshimura K: Mammographic changes after fat transfer to the breast compared with changes after breast reduction: a blinded study. Plast Reconstr Surg 129(5): 10291038, 2012.

51 Pulagam SR, Poulton T and Mamounas EP: Long-term clinical and radiologic results with autologous fat transplantation for breast augmentation: case reports and review of the literature. Breast J 12(1): 63-65, 2006.

52 Kwak JY, Lee SH, Park HL, Kim JY, Kim SE and Kim EK: Sonographic findings in complications of cosmetic breast augmentation with autologous fat obtained by liposuction. J Clin Ultrasound 32(6): 299-301, 2004.

53 Gutowski KA and Force AFGT: Current applications and safety of autologous fat grafts: a report of the ASPS fat graft task force. Plast Reconstr Surg 124(1): 272-280, 2009.

54 Illouz YG and Sterodimas A: Autologous fat transplantation to the breast: a personal technique with 25 years of experience. Aesthetic Plast Surg 33(5): 706-715, 2009.

55 Serra-Renom JM, Munoz-Olmo JL and Serra-Mestre JM: Fat grafting in postmastectomy breast reconstruction with expanders and prostheses in patients who have received radiotherapy: formation of new subcutaneous tissue. Plast Reconstr Surg 125(1): 12-18, 2010.

$56 \mathrm{Li} \mathrm{X}$ and Guo X: Progressive fat necrosis after breast augmentation with autologous lipotransfer: a cause of longlasting high Fever and axillary lymph node enlargement. Aesthetic Plast Surg 39(3): 386-390, 2015.

Received July 3, 2016

Revised July 27, 2016

Accepted August 1, 2016 